\title{
LA SUSPENSIÓN Y EXTINCIÓN DE CONTRATOS TEMPORALES DURANTE LA CRISIS SANITARIA DEL COVID-19
}

Fco. Ramón Lacomba Pérez
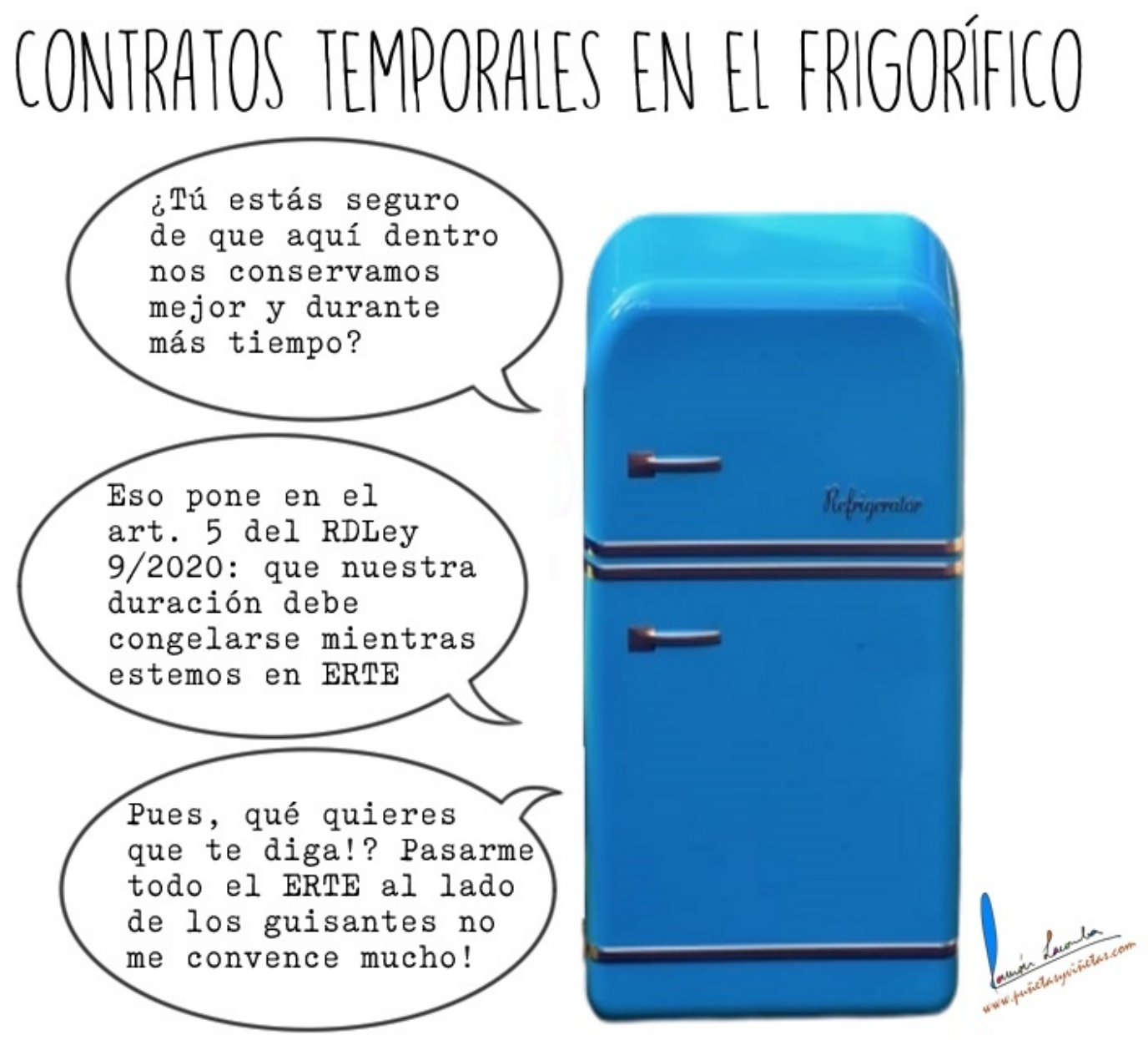

IUSLabor 2/2020, ISSN 1699-2938, p. 42-47

DOI. DOI. 10.31009/IUSLabor.2020.i02.02

Fecha envío: 29.6.2020 | Fecha aceptación: 2.7.2020 


\section{Introducción}

El artículo 5 RDLey 9/2020 impide la extinción prevista de los contratos temporales, incluidos los formativos, de relevo e interinidad, afectados por un ERTE COVID-19 de suspensión de contratos (por fuerza mayor o por causas económicas, técnicas, organizativas o de producción) al interrumpir el cómputo de su duración pactada y de su duración máxima. El RDLey 24/2020 extiende la vigencia de dicha suspensión hasta el 30 de septiembre de $2020^{1}$. El argumento para justificar esta medida es que la paralización de la actividad económica, derivada del COVID-19, imposibilita que alcancen el objeto para el que fueron suscritos.

Con esta medida se detiene el tiempo (tanto como dure el periodo suspendido) para dos cómputos (retrasando así las fechas de extinción): el de la duración pactada y el de la duración máxima del contrato.

\section{La Duración Pactada Suspendida Del Contrato Temporal}

El cómputo de la "duración pactada" del contrato, dentro de su duración máxima permitida, se verá detenido dependiendo de la modalidad de contrato de que se trate:

\subsection{Contrato eventual por circunstancias de la producción}

El contrato eventual por circunstancias de la producción es un contrato a término ${ }^{2}$, es decir, que acaba -si así se pactó- a los 6 meses, con independencia de la vigencia de causa de temporalidad que lo haya justificado ${ }^{3}$. Al haberse interrumpido el cómputo, esa duración acordada de 6 meses se verá incrementada en tantos días como haya durado la suspensión. Como señala el Oficio de la DGT de 11.04.2020 (DGT-SGON-850CRA), la expiración del plazo pactado o previsto no va a poder

\footnotetext{
1 Por tanto, en los supuestos en los que el ERTE por causas ETOP se extienda más allá del 30.09.2020, desde esa fecha, y con indepencia de que el contrato siga suspendido, se iniciará la recuperación de los días de suspensión aplicados durante el estado de alarma.

${ }^{2}$ Así lo recuerda, por ejemplo, la STS (Social) 25-07-2014 (RCUD 1405/2013) cuando señala que "esta Sala ha declarado en la sentencia de 4 de febrero de 1999 (R-2022/1998), que el artículo 15.1.b) del Estatuto de los Trabajadores debe interpretarse en el sentido de que el contrato temporal requiere necesariamente un término y que éste rige la vigencia del contrato, al margen de las circunstancias que justifican el recurso a la contratación temporal, lo que obliga a las partes, y en especial a la empresa, que es la que cuenta con la información necesaria para ello, a establecer siempre un término o someterse al máximo, sin perjuicio del recurso a las prórrogas cuando la duración fijada no supera la máxima y subsista la necesidad de trabajo temporal...”.

${ }^{3}$ Es decir, ordinariamente, dado que tiene una fecha pactada de finalización, dentro de la duración máxima, habría de acabar en esa fecha con independencia de que el incremento de pedidos, por ejemplo, que justificó el contrato haya finalizado o se extienda más tiempo.
} 
operar como causa extintiva porque "lo que se interrumpe es el ingrediente temporal del contrato suspendido y no cabe la extinción de los mismos durante dicho periodo por transcurso del plazo previsto, cuyo cómputo se restablece una vez concluya el periodo descrito".

A estos efectos, deberá tenerse en cuenta la siguiente distinción:

- Si el contrato tiene una fecha prevista de finalización posterior al fin del ERTE, aquella se retrasará tantos días como haya durado la suspensión del contrato por el ERTE (si la suspensión ha durado 10 días de marzo, 30 días de abril, 31 días de mayo y 30 días de junio, y el contrato debía acabar el 31 de julio, deberá retrasar su fecha de fin 101 días).

- Si, en cambio, el contrato tenía una fecha pactada de finalización que se habría producido durante la vigencia del ERTE, habrán de recuperarse los días de suspensión hasta esa fecha de fin (si la suspensión ha durado 10 días de marzo, 30 días de abril, 31 días de mayo y 30 días de junio, y el contrato debía acabar el 31 de mayo, deberá retrasarse su fecha de fin 71 días a partir del 1 de junio).

En todo caso, será conveniente comunicar dicha ampliación al trabajador cuando se reanude la prestación laboral o llegue el 30 de septiembre de 2020 (lo que suceda antes) (artículo 8.5 ET y artículo 2.2.b Real Decreto 1659/1998)

\subsection{Contratos de prácticas o el de para la formación y el aprendizaje}

Lo mismo sucede con la fecha de finalización pactada, dentro de su duración máxima, para contratos como el de prácticas o el de para la formación y el aprendizaje, que no finalizarán cuando estuviera previsto, sino un poco más tarde.

a) Contratos de obra o servicio determinado, de interinidad y de relevo

Ahora bien, en el caso de contratos como el de obra o servicio determinado, el de interinidad o el de relevo, esta norma no detiene el cómputo de la duración máxima del contrato, que sí queda necesariamente condicionada a la subsistencia de la circunstancia que justifica la contratación. Y así lo ha señalado el TS en su doctrina ya clásica al respecto y que recuerda a propósito de los contratos de puesta a disposición en la STS 04.02.1999 (RCUD 2022/1998) "la duración máxima del contrato... para la obra o servicio determinado y la interinidad por sustitución se remite a la subsistencia de la causa que motivó el respectivo contrato». 
Cómo señala el citado Oficio DGT 11.04.2020, para estas "otras causas válidas de extinción distintas de la expiración del plazo pactado o previsto... como la ejecución o realización de la obra o el servicio o la reincorporación del trabajador sustituido o extinción de la causa de reserva de un puesto de trabajo en el supuesto contratos de interinidad, habrá que estar al régimen legal previsto para las mismas". Así:

- "La interrupción del cómputo de la duración de los contratos temporales, incluidos los contratos formativos y el contrato de relevo, fundada en la excepcionalidad del estado de alarma causada por el COVID-19 no altera ni desnaturaliza dicha conclusión", por lo que la duración máxima no se detiene para ellos y podrán extinguirse cuando finalice su causa de temporalidad.

- “...En el contrato de obra o servicio determinado la causa de extinción será la terminación de la obra o servicio, y no la suspensión de la misma...", por lo que tampoco la duración máxima se detiene para estos contratos y podrán extinguirse cuando finalice su causa de temporalidad.

- Y “...en el caso de contratos de interinidad la duración del contrato de interinidad será la del tiempo que dure la ausencia del trabajador sustituido con derecho a la reserva del puesto de trabajo, siendo objeto de interrupción y posterior reanudación de su cómputo, en el caso de que se trate de interinidad por cobertura de vacantes", por lo que también este contrato se extinguirá al margen de la interrupción de la duración de los contratos temporales establecida. La misma conclusión procederá con respecto a los contratos de relevo.

En definitiva, el artículo 5 RDLey 9/2020 no está descausalizando los contratos temporales, sino ampliando indirectamente la duración pactada donde sea posible pactarla, y no lo es en el caso de los contratos de interinidad, obra o servicio o relevo, porque la misma depende de un factor externo.

\section{La duración máxima suspendida del contrato temporal}

El otro cómputo que el artículo 5 RDLey 9/2020 detiene es el de "los períodos de referencia" del contrato, es decir, en de las duraciones máximas permitidas:

- En el caso del contrato eventual por circunstancias de la producción, señala el artículo 3.2 RD 2720/1998 que la “duración máxima de este contrato será de seis meses dentro de un período de doce meses" pudiendo ampliarse por Ccol aunque, en tal caso, no podrá establecerse "un período de referencia que exceda 
de dieciocho meses ni una duración máxima del contrato que exceda de las tres cuartas partes del periodo de referencia legal o convencionalmente establecido”. Bien, pues, con esta interrupción que introduce el artículo 5 RDLey 9/2020, ese límite podrá excederse tantos días como haya durado la suspensión.

- El contrato por obra o servicio determinado no puede tener una duración superior a tres años (ampliable hasta doce meses más por convenio colectivo), pero con esta interrupción podrá extenderse un tiempo más (el que haya durado la suspensión) (artículo 15.1.a ET)

- El contrato en prácticas no podrá exceder de dos años (artículo 11.1.b ET), de manera que ese límite podrá superarse en tantos días como haya durado la suspensión.

- El contrato para la formación y el aprendizaje tiene una duración máxima de tres, que podrá excederse tantos días como haya durado la suspensión (artículo 11.2.b ET).

- En el caso del contrato de relevo, se prevé que si, al cumplir dicha edad, el trabajador jubilado parcialmente continuase en la empresa, el contrato de relevo que se hubiera celebrado por duración determinada podrá prorrogarse mediante acuerdo con las partes por "periodos anuales", extinguiéndose en todo caso al finalizar el periodo correspondiente al año en el que se produzca la jubilación total del trabajador relevado. Esos períodos anuales podrían verse ampliados en tantos días como haya durado la suspensión, si todavía no ha accedido el jubilado parcial a la jubilación total.

- En el caso del contrato de interinidad, el artículo 4.2 RD 2720/1998 prevé que la duración del contrato de interinidad por vacante en procesos de selección de personal será el tiempo que dure ese proceso, con un "máximo de tres meses", y sin que pueda celebrarse otro contrato de interinidad para ese mismo proceso de selección. Este período de referencia de 3 meses, en este supuesto específico, se vería ampliado indirectamente en tantos días como haya durado la suspensión.

\section{La finalización de contratos temporales y el cumplimiento del compromiso de mantenimiento del empleo}

La Disposición Adicional Sexta del Real Decreto-ley 8/2020 ha introducido un condicionante temporal a la decisión empresarial de extinción de contratos de 
trabajo. En concreto, la empresa que se haya beneficiado de las exoneraciones de cuota previstas para las empresas que se han acogido a un ERTE por fuerza mayor o un ERTE por causas objetivas (este último, tras el RDLey 24/2020), deberá reintegrar tales cuotas exoneradas, más recargos e intereses, si extingue contratos de trabajadores regulados durante los 6 meses siguientes a la reanudación de la actividad (o la entrada en vigor del RDLey 24/2020, en el caso de los ERTEs por causas objetivas).

El apartado 2 de dicha Disposición Adicional aclara que, entre esas extinciones penalizadas, no se encuentra la finalización de contratos temporales por expiración del tiempo convenido o por la realización de la obra o servicio que constituye su objeto.

Pero, la misma norma añade que tampoco constituye incumplimiento del compromiso de mantenimiento del empleo la extinción de contratos temporales "cuando no pueda realizarse de forma inmediata la actividad objeto de contratación”. Es decir, contempla la norma el caso, nada extraño, de que la suspensión de la actividad durante el ERTE haya hecho que desaparezca el objeto del contrato temporal que, sin embargo, por mor del artículo 5 RDLey 9/2020 y la suspensión de su duración, la empresa debe mantener.

Pues bien, en tal caso, la extinción del contrato temporal, por pérdida de su objeto, sin esperar a recuperar el tiempo de suspensión del contrato, no supondrá un incumplimiento del compromiso de mantenimiento del empleo. Ahora bien, para que opere este efecto, cómo deberá la empresa ejecutar las extinciones por esta causa.

La empresa debería, en tales casos, acometer despidos objetivos individuales o colectivos (dependiendo del número de afectados dentro de los 90 días computables), asumiendo el coste indemnizatorio correspondiente (20 días de salario por año trabajado con el tope de 12 mensualidades, conforme al artículo 53 ET) y haciendo constar que la causa de extinción es la productiva prevista expresamente en la Disposición Adicional Sexta, que "no puede realizarse de forma inmediata la actividad objeto de contratación". 